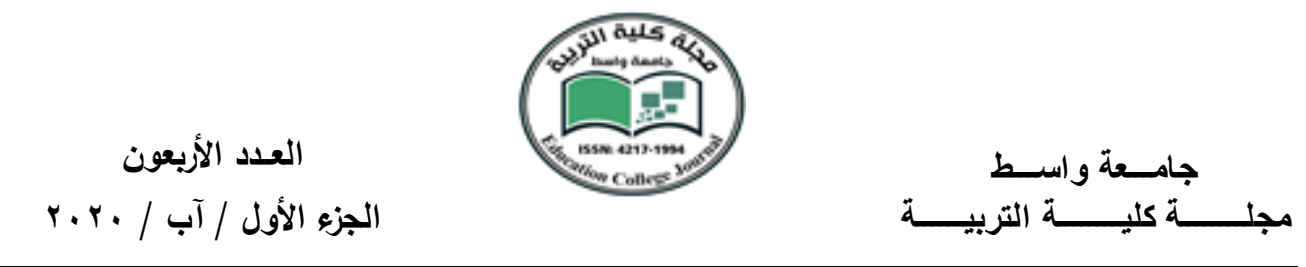

التحليل الجغرافي لزراعة أشجار الرمانيات والعنب في محافظة واسط

م.م خلود حيلر لازم ا.م.د شاكر مسير لفته الزاملي

جامعة وإسط / كلية التربية للعلوم الانسانية

المستخلص

تعد أشجار الرمانيات والعنب من الاشجار ذات القيمة الغذائية للأنسان، إذ عرفة أهميتها منذ القدم ومع أرتقائه سلم الحضارة وأرتفاع مستوى معيشته ، إذ أحتلت هذه الاشجار مكانة متميزة في غذائه وأزدادت حاجته لها لللك أخذ يبحث عن أساليب جديدة لزيادة انتاجها لتلبية متطلباته، تهدف الدراسة الى معرفة التباين في توزيع أعداد أشجار الرمانيات في محافظة واسط ، ومامدى تأثير العوامل الطبيعية والبشربة والحياتية في تباينها من منطقة الى أخرىوبناءً على هذا تم دراسة التحليل الجغرافي لزراعة أثنار الرمانيات والعنب في محافظة واسط لمعرفة أهم السبل لنجاح وفنشل هذه الزراعة في منطقة الدراسة، وقد أعتمد على البيانات الحكومية من قبل الشعب الزراعية ومديرية زراعة واسط ومن ثم أستخدمت التحليل الاحصائي والمنهج المحصولي والوصفي الذي عزز بالخرائط مدى التباين في توزيع هذه الاشجار منأثزاً بالعوامل الطبيعية إذ يعد سطح منطقة الدراسة الذي هو

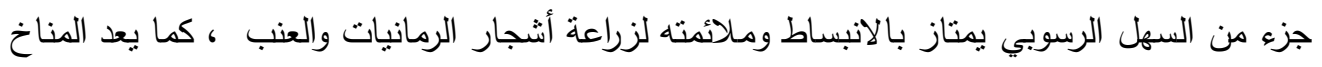
له تأثير على الأشجار ولاسيما الضوء ودرجات الحرارة التي تحتاجها كلن حسب منطلبات هذه الاشجار، كما تعد الامطار والرياح والعواصف الترابية تنبب خسارة للانتاج نتيجة أحتراق أجزاء من الورقة فضلا عن غلق الفتحات ، وأن معرفة نوعية الترب التي تحتاجها هذه الاشجار . الكلمات المفتاحية: الرمانيات والعنب من الاشجار ذات القيمة الغذائية للأنسان.

\title{
Abstract
}

Pomegranate and grape trees are among the trees that have a nutritional value for the human being, as man has known its importance since ancient times and with its elevation of the ladder of civilization and its high standard of living, as these trees occupied a distinguished position in their food and their need increased, so he began looking for new methods to increase their production to meet his requirements, the study aims to Knowing the variation in the number of pomegranate trees in Wasit governorate, and the extent to which natural, human and life factors influence their variations from one region to another. Agriculture in the study area, the researcher relied on government data by the agricultural people and the Wasit Agriculture 

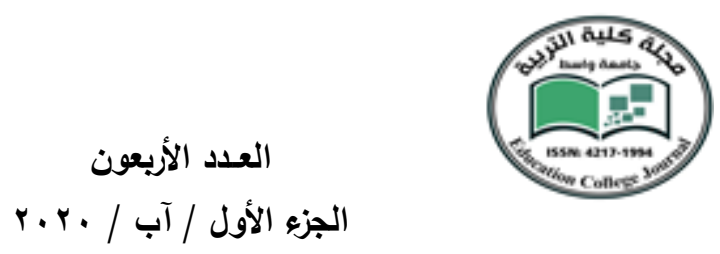

Directorate and then used the statistical analysis and the descriptive and cropping approach that strengthened with maps the extent of variation in the distribution of these trees affected by natural factors as the surface of the study area which is part of the sedimentary plain is characterized by flatness And its suitability for growing pomegranate trees and grapes, as the climate has an effect on trees, especially light and temperatures, which are needed by all of them according to the requirements of these trees. Also, rain, wind, and dust storms cause loss of production as a result of burning parts of the water $\mathrm{Ge}$ as well as the closure of the openings, and know the quality of the soil that you need these trees.

Key words: Pomegranates and grapes are trees of nutritional value to humans.

المقدمة

أن أنثجار الرمانيات والعنب تعد من المحاصيل الزراعية المهمة التي تساهم في أرتقاع

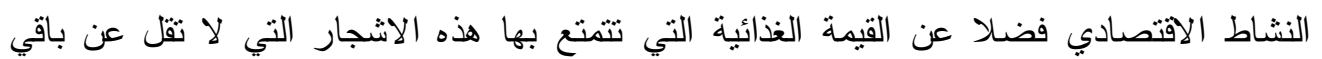

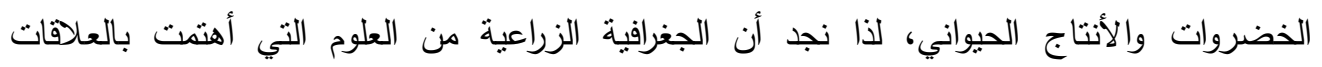

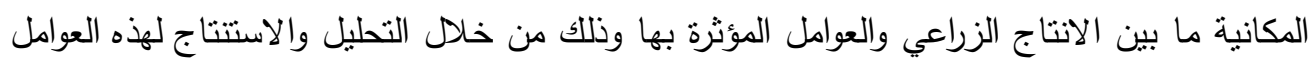

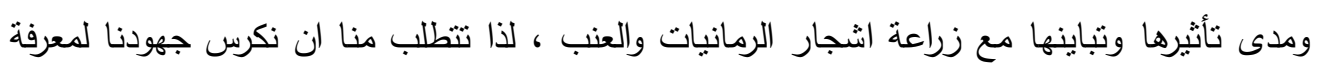

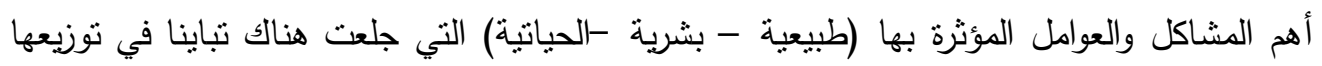

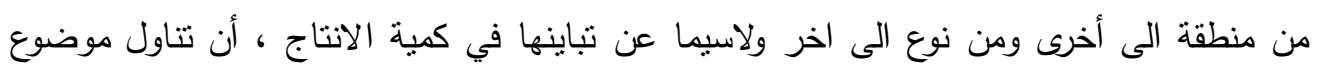

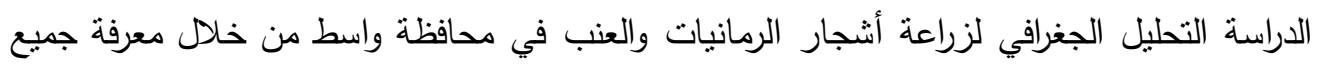

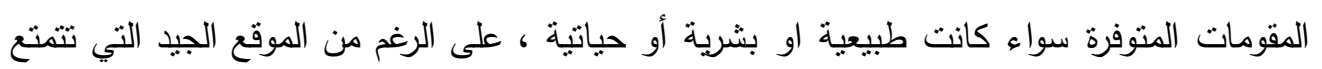
به محافظة واسط لكونها تقع ضمن منطقة السهل الرسوبي. مشكلة البحث

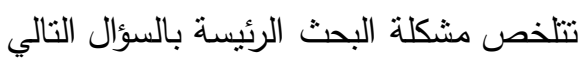

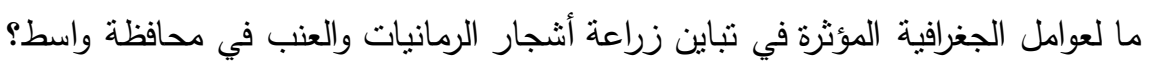

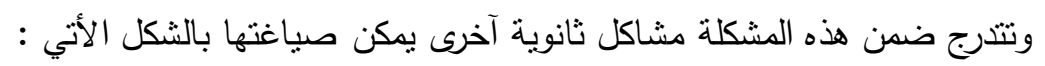

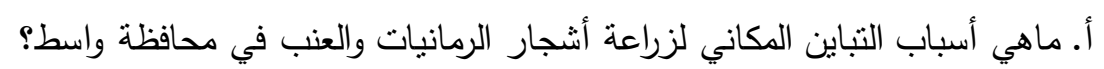

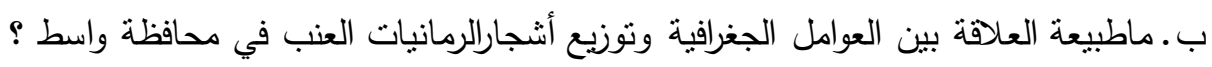

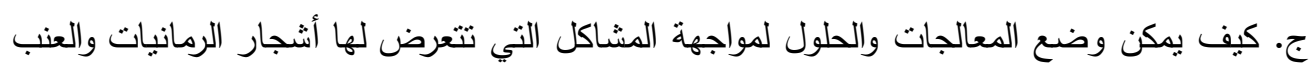
في محافظة واسط ؟ جن 
العدد الأربعون

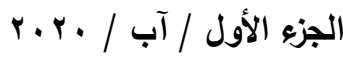

جامسـعة واســط

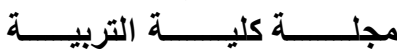

فرضية البحث

تعد فرضية البحث اجابة اولية على مشكلة البحث نثير الى التعميمات التي لم تثبت صحتها بعد لذا تتطلب منا في هذه الدراسة الوصول الى صحتها أو خطأها ومن هنا ينطلب أن نضع هذه الفئه الفرضية في صياغة على النحوالتالي الذي تتمثل فرضية البحث الرئيسة بالآتي .

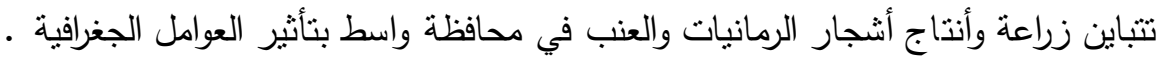
أ. تتباين المساحات المزروعة بأثجار الرمانيات والعنب ما بين الاقضية والنواحي كلن حسب المساحة

المخصصة للزراعة فيها.

ب.تتباين أعداد اشجار الرمانيات والعنب كما ونوعا في نوزيعها متأثرة بعلاقتها مع العوامل الجغرافية في محافظة واسط.

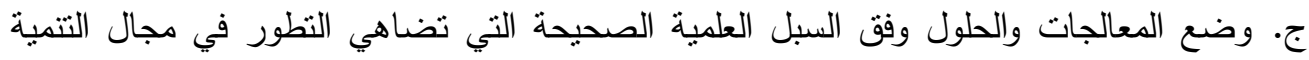

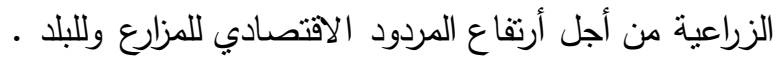

حدود منطقة الدراسة

تقع محافظة واسط في الجزء الاوسط من السهل الرسوبي الذي يحتل الاقسام الوسطى والجنوبية من العراق ومركزها مدينة الكوت وتبعد VY اكم من العاصمة بغداد تحدها محافظة ديالى وبغداد من الثمال ومحافظة ميسان التي تبعد ج.بكم ومحافظة ذي قار عـ.rكم من الجنوب ومن الغرب محافظة بابل التي يفصلها عنها كV كم والى جنوبها الغربي محافظة الديوانية التي تبعد عنها

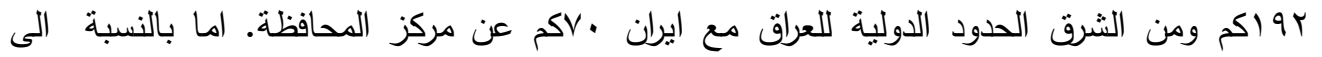

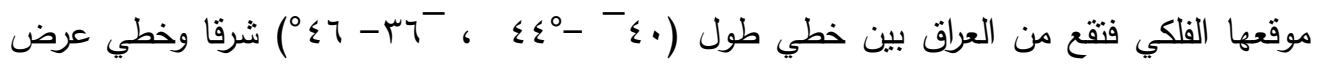

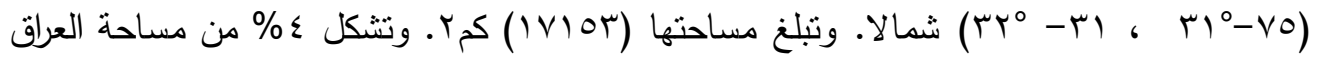

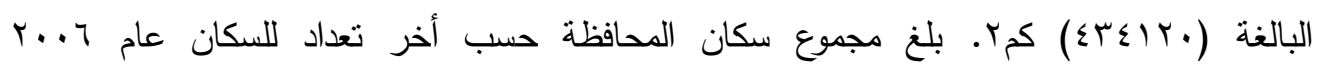

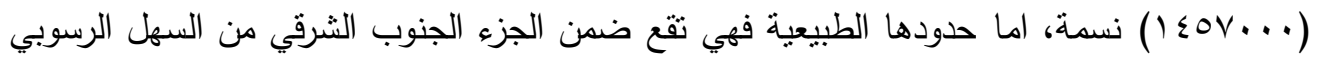

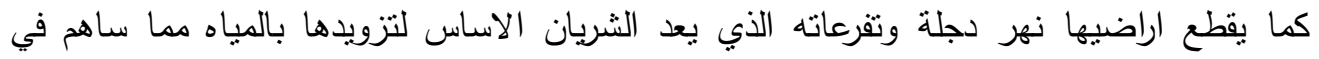

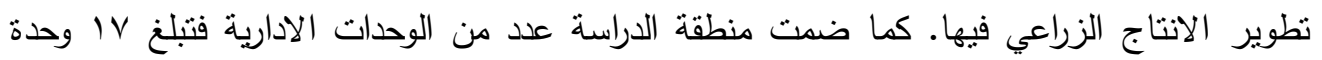
أدارية بين قضاء وناحية ،اذ تتكون من (T) اقضية وأحدى عثر ناحية كما في الخريطة (1). 


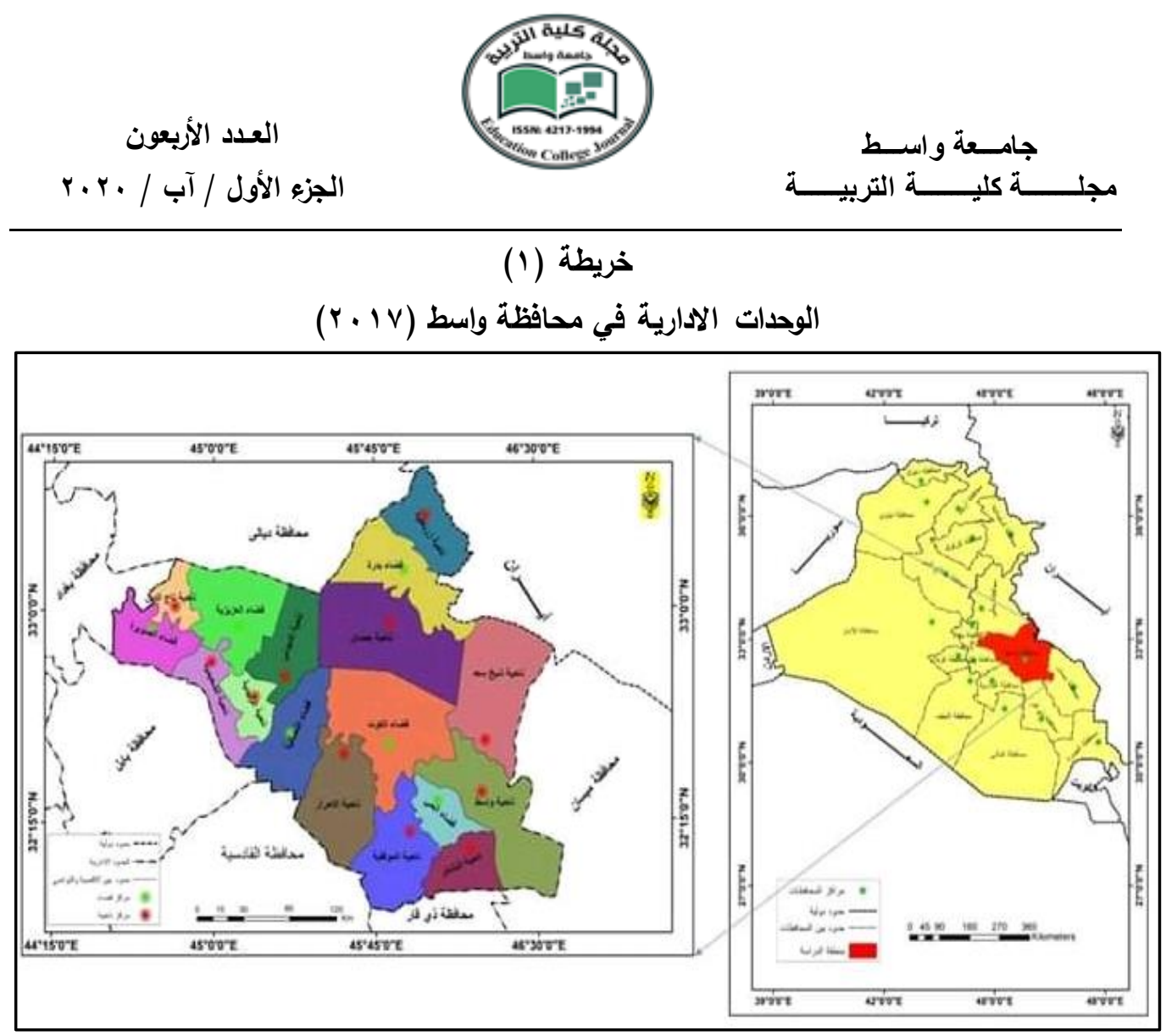

المصدر : من عمل الباحثان بالاعتماد على الخريطة الادارية للعرلق ذات مقياس رسم ا: . . . .

العوامل الطبيعية والبشرية والحياتية المؤثرة لزراعة أشجار الرماتيات والعبب

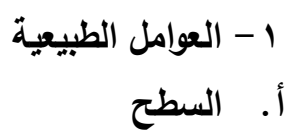

أن التركيب الجيولوجي لمنطقة الدراسة والتي هي جزء من السهل الرسوبي كان نتيجة من الحركات التكتونية للجبال منذ مليوني سنة والى يومنا هذا وهي مستمرة لهذه الحركات ولكن ببطئ شديد عما كانت سابقا التي نتج عنها المظاهر الجيومورفولوجية الحديثة بمنطقة السهل الرسوبي من تلال وجبال وسهول ومنخفضات وتغير في مجاري الانهار (1). القسم الاول - ينحدر شمالي شرقي منطقة الدراسة الذي يتمنل بخط الكنتور (MV) م فوق مستوى سطح البحر الذي يمند نحو الاتجاه الجنوب الغربي عند خط الكنتور (ع ا) م . القسم الثاني - يمتذ هذا الانحدار نحو الثمال الغربي من منطقة الدراسة أذ يمر بخط الكنتور (YT) م فوق مستوى سطح البحر بأتجاه الجنوب الثرقي الذي يمر بخط الكنتور (9 ( ) م فوق مستوى سطح - البحر 


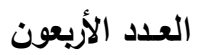

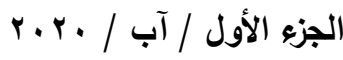

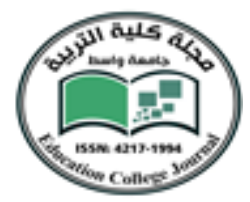

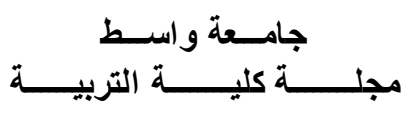

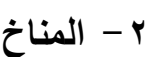

للمناخ تأثير كبير جدا لتحديد انواع المحاصيل التي يمكن زراعتها في منطقة دون غيرها، كنلك

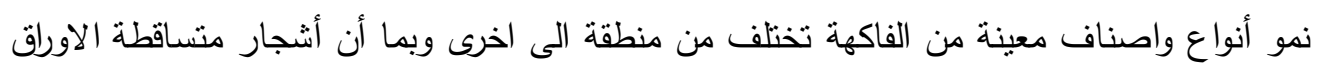

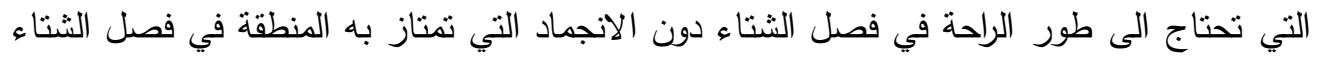

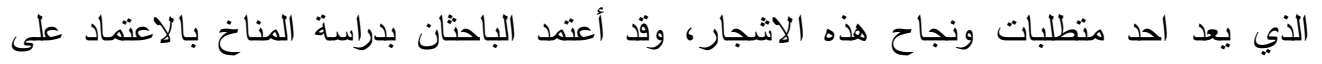

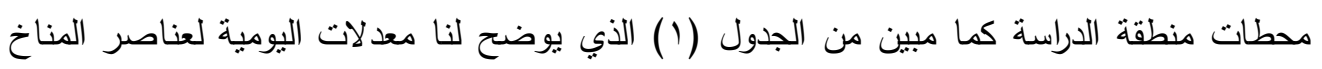

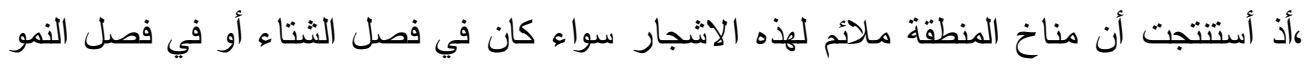
وهو فصل الصيف أذ تنمو وتتضج الثمار حتى يحين موعد قطوفها.

جدول (1)

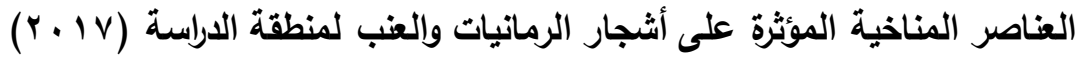

\begin{tabular}{|c|c|c|c|c|c|c|}
\hline للرياح م/ثاث & 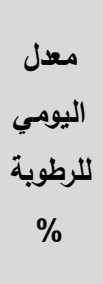 & ملثموع & للعدرارة مْ اليومي & للليوء & & الأشهر \\
\hline 2.72 & 70.26 & 24.41 & 11.16 & 6.37 & كانون الثاني & \\
\hline 3.01 & 59.6 & 15.69 & 12.96 & 7.23 & شباط & \\
\hline 3.23 & 48.29 & 13.94 & 17.66 & 8.28 & اذار & \\
\hline 3.06 & 41.40 & 14.04 & 24.78 & 8.70 & نيسان & \\
\hline 3.06 & 33.01 & 12.89 & 31.16 & 9.55 & مايس & \\
\hline 3.16 & 22.82 & $\mathbf{0}$ & 34.64 & 11.61 & حزيران & \\
\hline 4.55 & 21.94 & 0 & 36.82 & 11.76 & تموز & \\
\hline 4.44 & 22.44 & 0.15 & 35.94 & 11.62 & آب & \\
\hline 3.72 & 26.26 & 0.92 & 32.12 & 10.62 & ايلول & \\
\hline 3.41 & 35.88 & 9.04 & 25.80 & 8.40 & تثرين الاول & \\
\hline 2.78 & 58.96 & 24.76 & 18.24 & 7.39 & تثرين الثاني & \\
\hline 2.26 & 65.19 & 17.15 & 12.94 & 6.58 & كانون الاول & \\
\hline 3.26 & 42.17 & 11.08 & 24.44 & 9.01 & المعدل السنوي & \\
\hline
\end{tabular}

المصدر : وزارة النقل والمواصلات، الهيئة العامة للانواء الجوية والرصد الجوي، قسم المناخ، بذاد ، 
العدد الأربعون

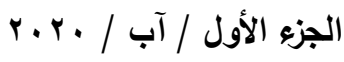

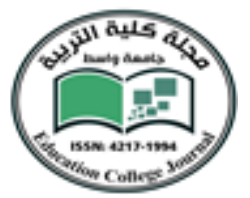

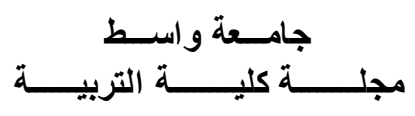

r

تقع منطقة الدراسة ضمن منطقة السهل الرسوبي وتمتاز هذه الترب جيدة نتيجة تكونها من ترسبات نهر دجلة في مواسم الفيضانات ، لكنها تنتوع من ناحية الجودة وملائمتها لهذه الزراعة إذ أنها تختلف ما بين منطقة وآخرى مما أثر هذا في التوزيع الجغرافي لأشجار الرمانيات والعنب ، فنجد المناطق التي تحتوي على ترب غنية بالمواد العضوية والمعدنية وبخصوبتها وتصريفها الجيد كانت تتركز فيها البساتين وأثجار الرمانيات والعنب ولاسيما تربة كتوف الانهار التي كانت على مساحات واسعة متاخمة مع ضفاف الانهار التي تمتد من الجهات الثمالية الغربية بأتجاه الجنوب الغربي وذلك لخلوها من الاملاح ولجودة تصريفها فضلا عن انخفاض مستوى المياه الجوفية كما مبين من الخريطة

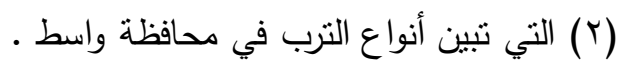

\section{خريطة (r)}

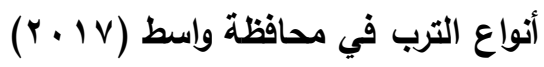

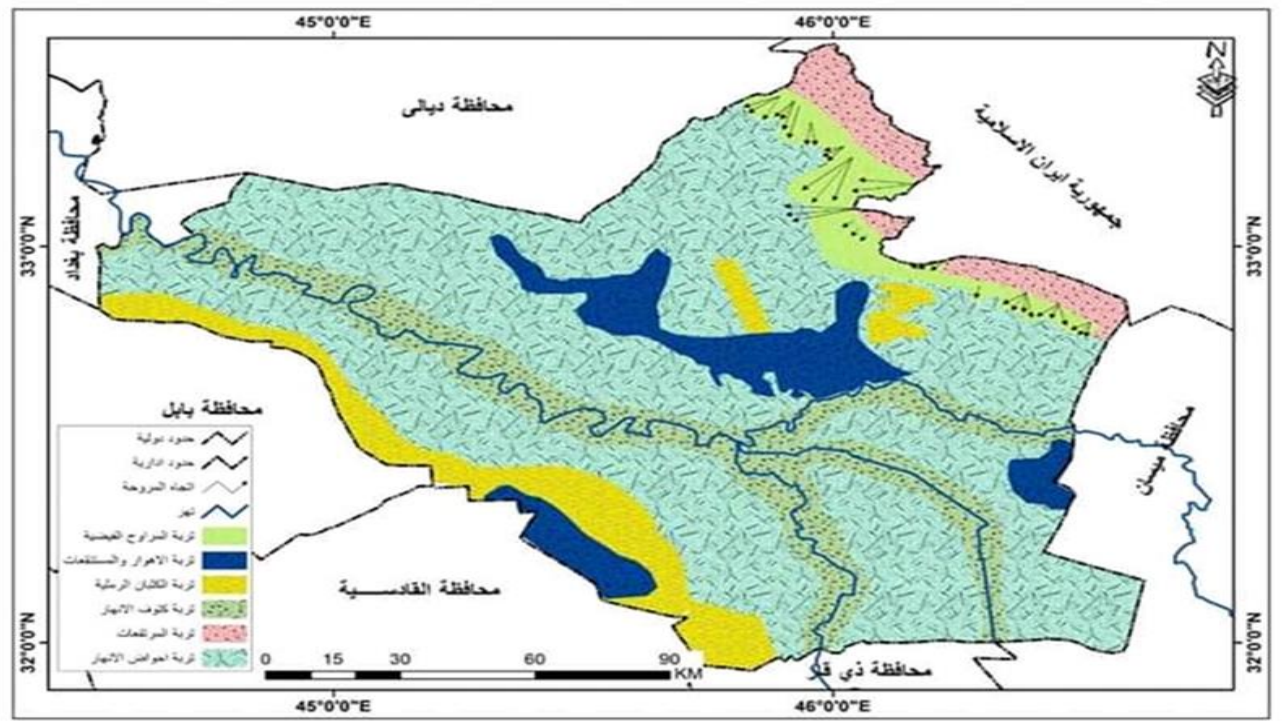

المصدر :- من عمل الباحثان بالاعتماد على الخريطة الادارية للعراق ذات مقياس رسم 
العدد الأريعون

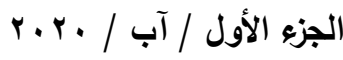

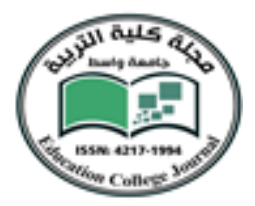

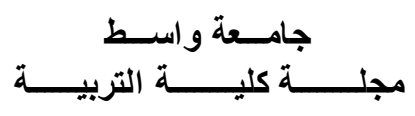

جامسـعة واســط كلئ

ع - الموارد المائية

تعد الموارد المائية من الاساسيات المهمة لنجاح هذه الزراعة وأن المياه السطحية في منطقة

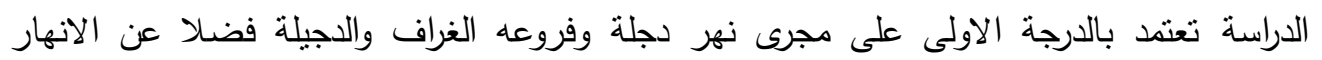
الموسمية الاتية من الجهات الشرقية للمنطقة فضلا عن الاهوار الموجودة في المنطقة الذي غذت التهائ

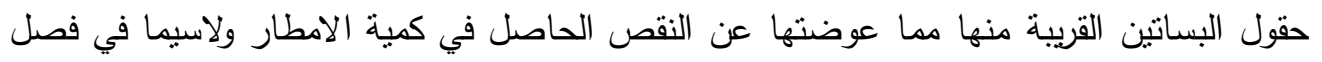
الصيف كما مبين من الخريطة (ب) الذي تمنل المياه السطحية بمنطقة الدراسة.

\section{خريطة (r)}

المياه السطحية في محافظة واسط (r. Y (Y)

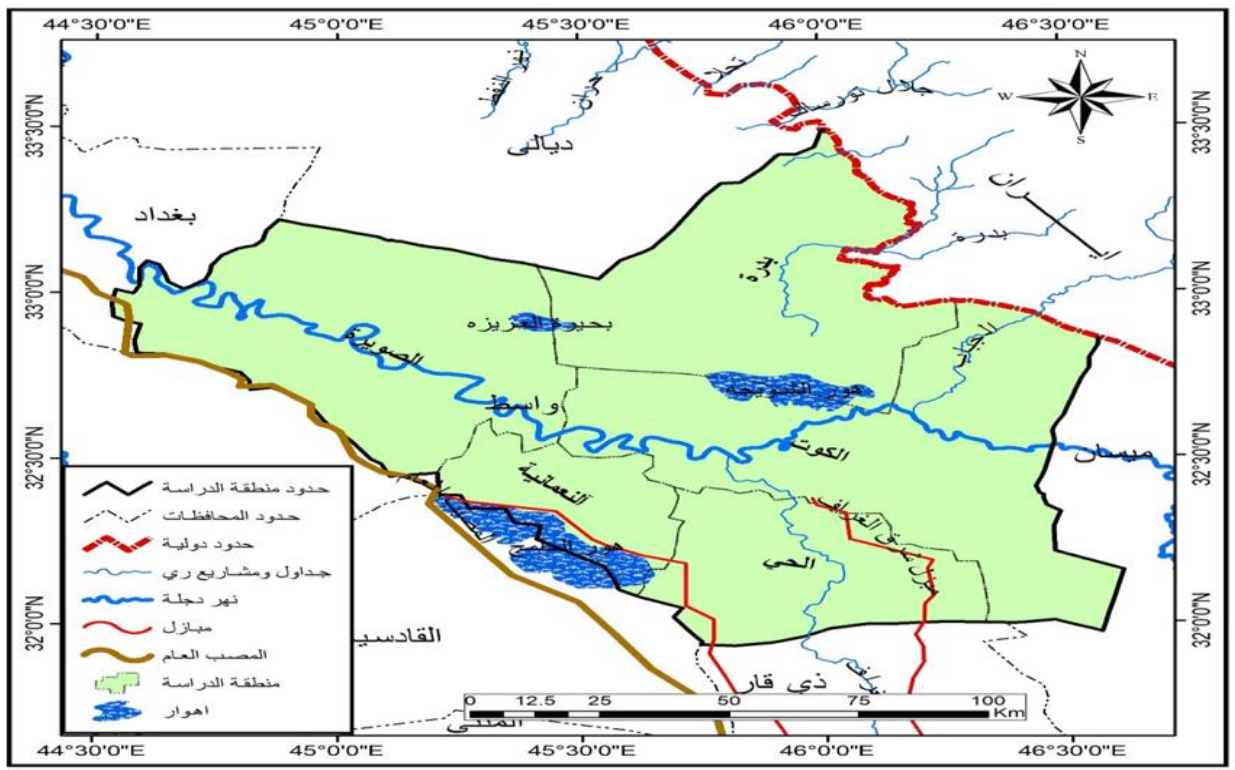

المصدر:- من عمل الباحثان بالاعتماد على الخريطة الادارية للعرلق ذات مقياس رسم

ه - النبات الطبيعي

نجد بأن النبات الطبيعي في منطقة الدراسة يكون متباينا مكانبا وزمانيا حسب الظروف الطبيعية التي

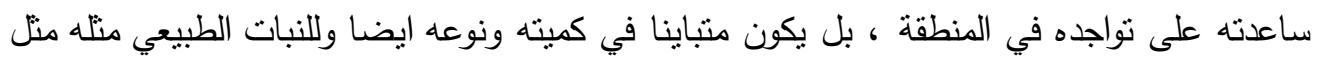

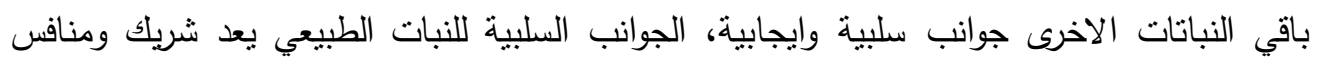


العدد الأربعون

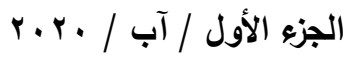

للمحاصيل الزراعية واشجار الفاكهة من حيث الغذاء والماء مما يسبب اضعاف للنباتات الاخرى وبالتالي قلة انتاجيتها ، أما الجانب الايجابي يساعد على خصوبة التربة ويمنع انجرفها.

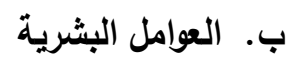

تمتاز العوامل البشرية بتغير اسرع من العوامل الطبيعية التي تتصف بالثبات نوعا ما ، فضلا عن التذاخل فيما بينها وتباينها من مكان الى اخر، وان تاثير العوامل البشرية بالانتاج الزراعي يظهر بشكل واضح ومتصاعد مع الارتقاء الحضاري للانسان وتقدمه العلمي(r). وتعتمد زراعة اشجار الرمانيات والعنب على الايدي العاملة الذي يقدر عددهم (90) نسمة والخبرة الفنية الماهرة بالزراعة لدى الفلاح والعناية الفائقة من حيث مكافحة الحشرات والامراض والسقي والتقليم والجني

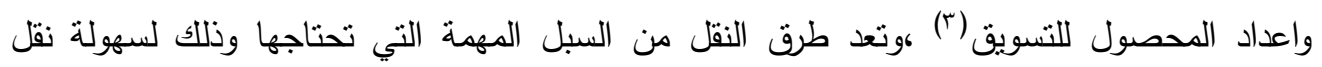
المحصول باسرع وقت ممكن كما توفير وسائل النقل الحديثة والمبردة أذ تساهم في تقليل تلف الثمار

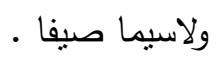

\section{ج. العوامل الحياتية}

إذ تتعرض اشجار الرمانيات والعنب الى الكثير من الآفات والامراض داخل البستان أو خارجه اذا لم تجد عناية مواكبة له ولاسيما في فصول التكاثز وهجرة العديد من هذه الحشرات والامراض ، وتعد حشرة المن التي نتغذى على أوراقها وتعمل على تجعيدها والتوائها ، وهناك حشرة البق الدقيق الذي هني يصيب معظم اشجار الفاكهة وحشرة حفار الساق وذبابة البحر المتوسط ، ودودة ثمار الرمان التي تكافح برش المبيد في بداية حزيران (سفن) بخلطه مع الماء ، ومن أهم الامراض التي تتعرض لها هذه الاشجار هي مرض التعفن البني والمعالجة تكون برش الاشجار المصابة بالا نتراكول بخلطه مع الماء ، أما حشرات ديدان أوراق العنب ودودة العناقيد وقفاز العنب وتكون المكافحة في شهر حزيران برش المبيدات (سفن أوديازتيون) بخلطه مع الماء ، أما الاراضي التي تصيب بها أثجار العنب بالبياض الدقيقي ومرض البياض الزغبي وموت الافرع يجب أجراء اللازم فيها للحد من أنتشارها كما

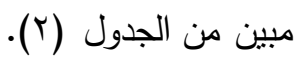




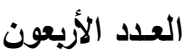

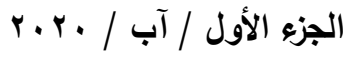

جامسعة واسـط

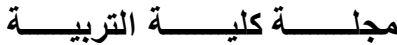

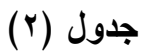

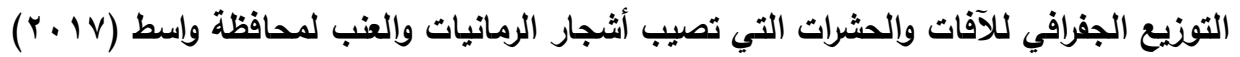

\begin{tabular}{|c|c|}
\hline الآقات والحشرات & الوحدات الادارية \\
\hline الدوياس -العنكبوت - حفار الساق - دودة الثمار & قضاء الكوت \\
\hline البياض الزغبي - الذبابة البيضاء-البياض الدقيق & ن احية الاحرار \\
\hline لايوجد & ناحية واسط \\
\hline العنكبوت -الغبار - الصدا - البياض الدقيق - الحشرة القشرية & قضاء النعمانية \\
\hline الغبار - الذبابة البيضاء -التعفن & ناحية الموفقية \\
\hline 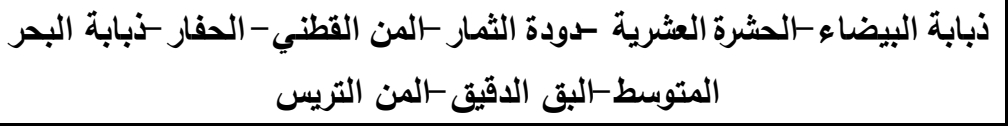 & قضاء الحي \\
\hline حفار الورق - ذبابة الياسمين & ناحية الدبوني \\
\hline الحميرية-الذبابة البيضاء -التصمغ & ناحية الحفرية \\
\hline الحفار - المن القطني - العناكب & قضاء العزيزية \\
\hline 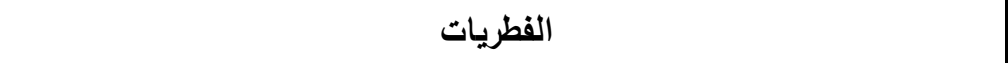 & 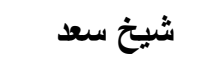 \\
\hline الدوياس-الذبابة البيضاء-المن القطني-ذبابة البحر المتوسط & قضاء الصويرة \\
\hline لايوجد & ناحية الدجيلة \\
\hline لايوجد & ناحية جصان \\
\hline لايوجد & ناحية زرياطية \\
\hline ل الايوجل & ناحية الثحيمية \\
\hline
\end{tabular}

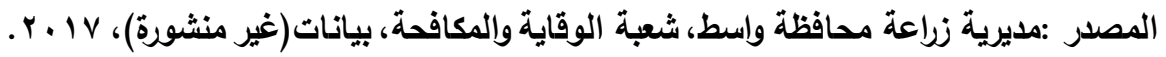

Fam Punicaceae العائلة الرمانية

Pomegranate الرمان

الاسم العلمي Punica وهي من الاشجار متساقطة الاوراق وتكون الاقرع أسطوانية مرنة أما

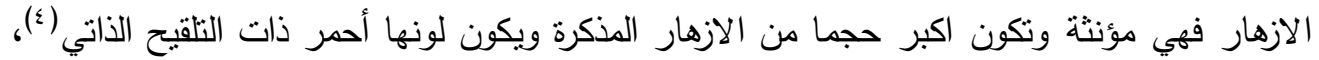

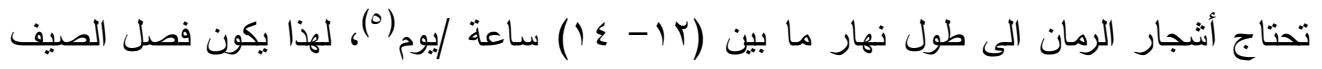

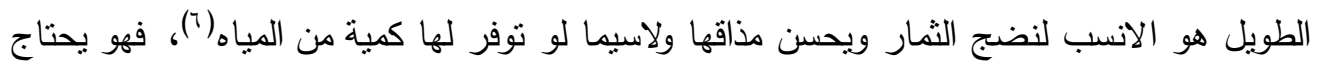
الى مناطق شديدة الحرارة والمعتلة الرطوبة ولاسيما فترة نضج الثمار صيفا وتقتصر حاجته الى

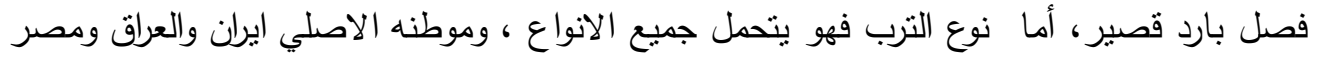


العدد الأربعون

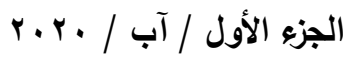

ومن ثم نقل الى أسبانيا (v)، تعد ثمار الرمان ذات قيمة غذائية عالية لأحتواه على العناصر والفيتامينات التي تفيد جسم الانسان فهو يعد منقي للام ومزيل الكولسترول ويكافح الاورام ، أما قشوره

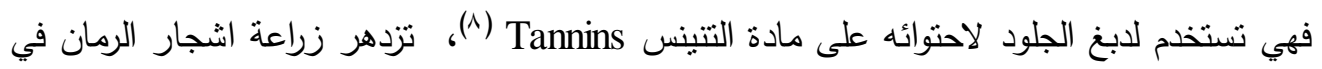

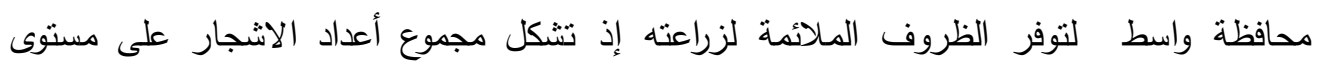

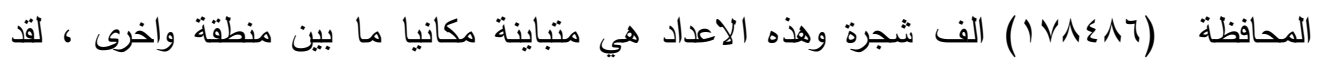
أظهرت هذا التباين المكاني قيمة الدرجة المعيارية الذي بلغت فيها قيمة الانحراف المعياري

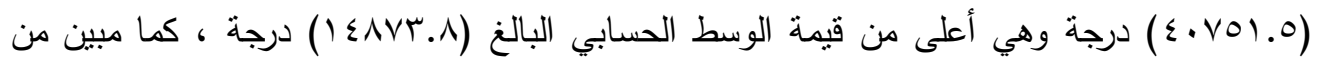
معطيات الجدول (ع) الذي يبين التوزيع الجغرافي لأعداد اشجار الرمان وكمية انتاجه حسب الوحدات الادارية للمحافظة إذ نبين لنا خمس مستويات كما توضحها خريطة (ع) : المستوى الاولى تقع بين (-דr..، -هr. •) ضم كل من الوحدات الادارية مركز قضاء النعمانية

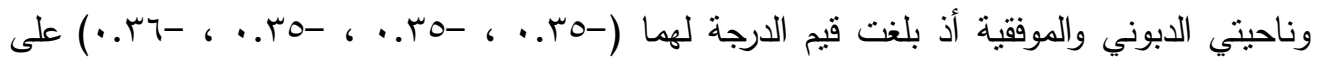

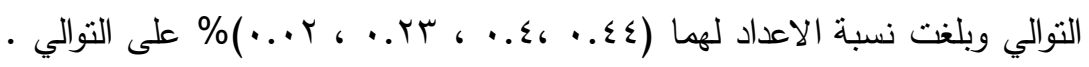

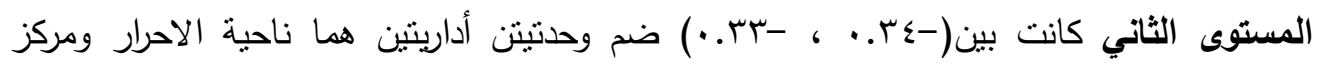

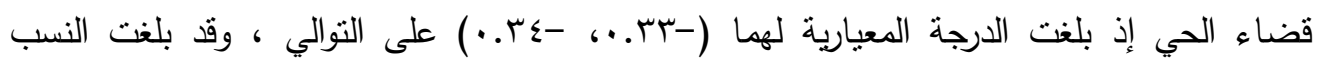
المئوية لأعداد الاشجار لهما (10.. ، 00. •) \% على التوالي . المستوى الثالث كانت بين (-r.. ، ، -9 (. ) ضم كل من الوحدات الادارية التالية مركز قضاء

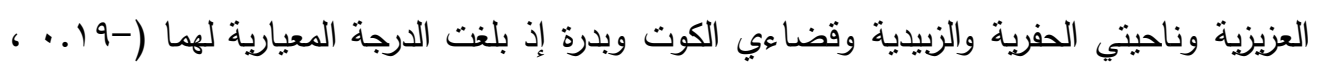

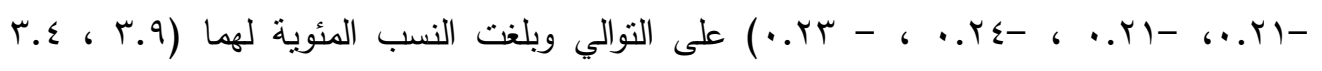

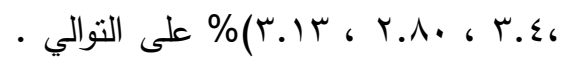

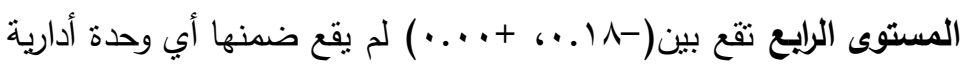

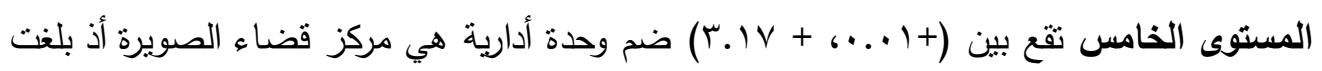

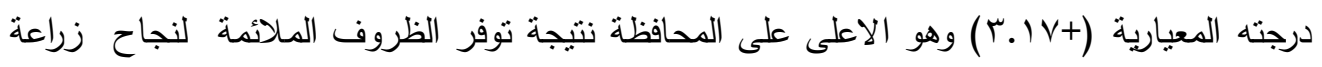

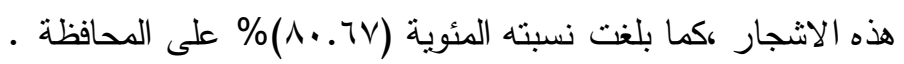
ولقد تميزت منطقة الدراسة بأرتفاع أعداد أثجار الرمان وهذا يرجح الى توفر الظروف البيئية الملائمة للاكثار أعدادها نظرا لما نوفره من مردود أقتصادي لأصحاب البساتين ،وكما أن هناك تباينا مكانيا

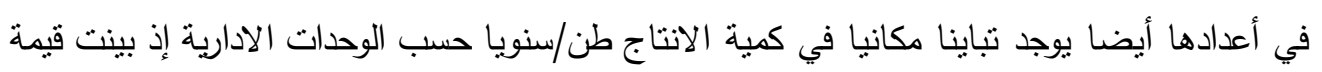

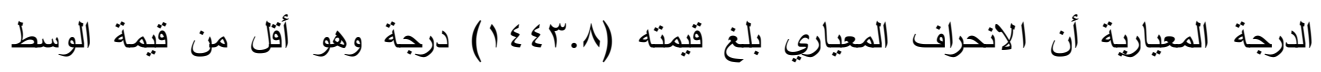


العدد الأربعون

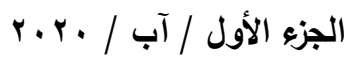

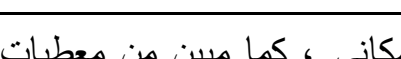

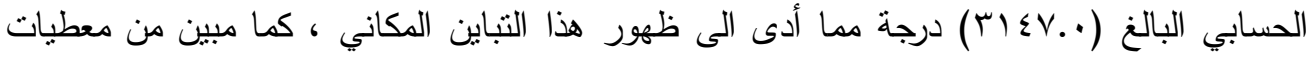

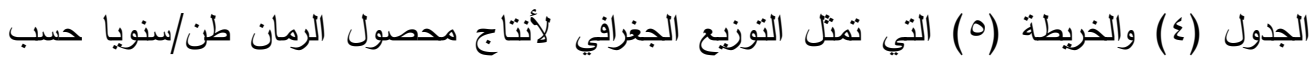

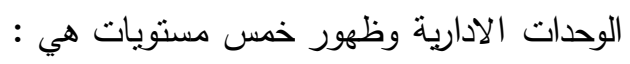

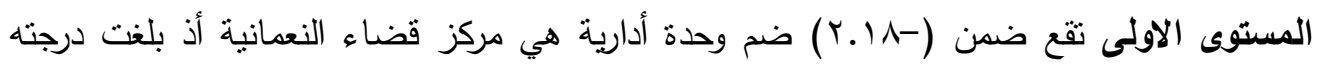

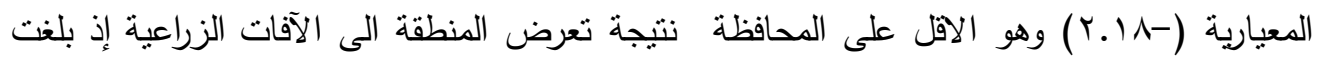

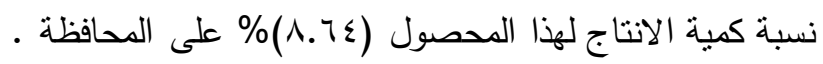

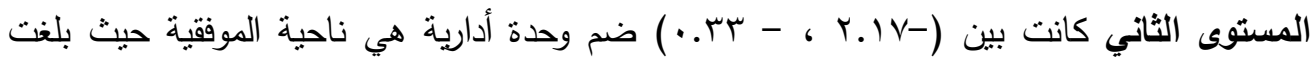

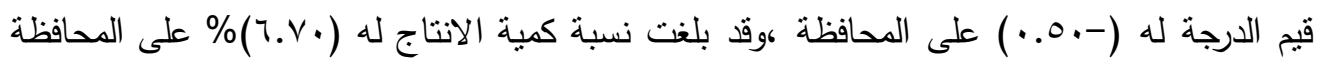


العدد الأريعون

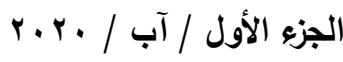

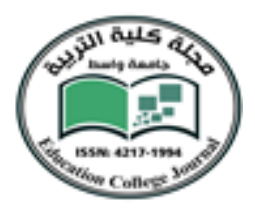

جدول (飞)

التوزيع الجغرافي لأعداد أشجار الرمان وكمية انتاجه كفم /دونم حسب الوحدات الادارية لمحافظة واسط

\begin{tabular}{|c|c|c|c|c|c|c|}
\hline \multicolumn{7}{|c|}{$(r+I V)$} \\
\hline$\%$ & الدرجة المعيارية & طن الانتاج & المئوية\% & الدرجة المعيارية & أعاد أثنجار & الوحدات الادارية \\
\hline A.rV & $. .11-$ & r৭१. & 2.80 & -0.24 & o... & قضاء الكوت \\
\hline-- & -- & -- & -- & -- & -- & ناحية واسط \\
\hline r.ru & 0.36 & צוצ' & 0.02 & -0.36 & o. & ناحية شيخ سعد \\
\hline $0.1 \leqslant$ & r.11- & riro & 0.44 & -0.35 & va. & قضاء النعمانية \\
\hline 0.19 & $. .1 r-$ & ratr & 0.85 & -0.33 & iro. & ناحية الاحرار \\
\hline$v . \leqslant 0$ & . I I- & rवq\& & 0.55 & -0.34 & 991 & قضاء الحي \\
\hline ร.v. & $.0 .-$ & $r \leqslant r \leqslant$ & 0.23 & -0.35 & Tr & ناحية الموفقية \\
\hline-- & -- & -- & -- & -- & -- & ناحية البشائر \\
\hline $0.1 \mathrm{r}$ & $. .10-$ & דוב ra & 3.13 & -0.23 & $04 .$. & قضاء بدرة \\
\hline-- & -- & -- & -- & -- & -- & ناحية جصان \\
\hline-- & -- & -- & -- & -- & -- & ناحية زرياطية \\
\hline 9.91 & צr & M. . & 80.67 & +3.17 & $1 \leqslant \ldots \ldots$ & قضاء الصويرة \\
\hline Q.rT &. .14 & . & 3.4 & -0.21 & 7119 & ناحية الزبيدية \\
\hline-- & -- & -- & -- & -- & -- & ناحية الثديمية \\
\hline 9.04 &.$r y$ & $r \leqslant \leqslant \wedge$ & 3.9 & -0.19 & v... & قضاء العزيزية \\
\hline A.vo & $\ldots .1$ & M170 & 3.4 & -0.21 & ITY & ناحية الحفرية \\
\hline V.AY & ..rY- & YAYA & 0.4 & -0.35 & vo. & ناحية الابوني \\
\hline \multirow[t]{3}{*}{$1 \ldots$} & & MTI & 100 & & $1 \vee \wedge \leqslant \wedge 4$ & المجموع \\
\hline & 3147.0 & \multicolumn{2}{|c|}{ الوسط الحسابي } & 14873.8 & \multicolumn{2}{|c|}{ الوسط الحسابي } \\
\hline & 1443.8 & \multicolumn{2}{|c|}{ الانحراف المعياري } & 40751.5 & \multicolumn{2}{|c|}{ الانحراف المعياري } \\
\hline
\end{tabular}

المصدر: من عمل الباحثان بالاعتماد على مديرية زراعة محافظة واسط ،شعبة التخطيط ،بيانات الانيط 


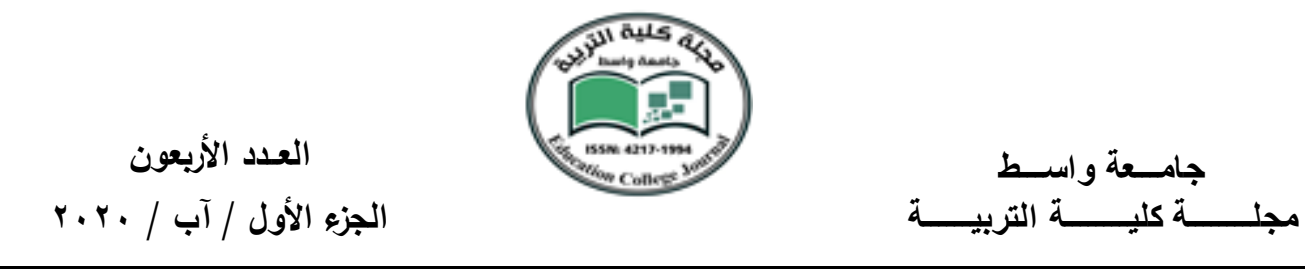

خريطة (๕)

التوزيع الجغرافي لأعداد أثنجار الرمان حسب الوحدات الادارية

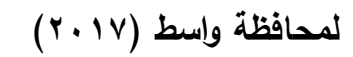

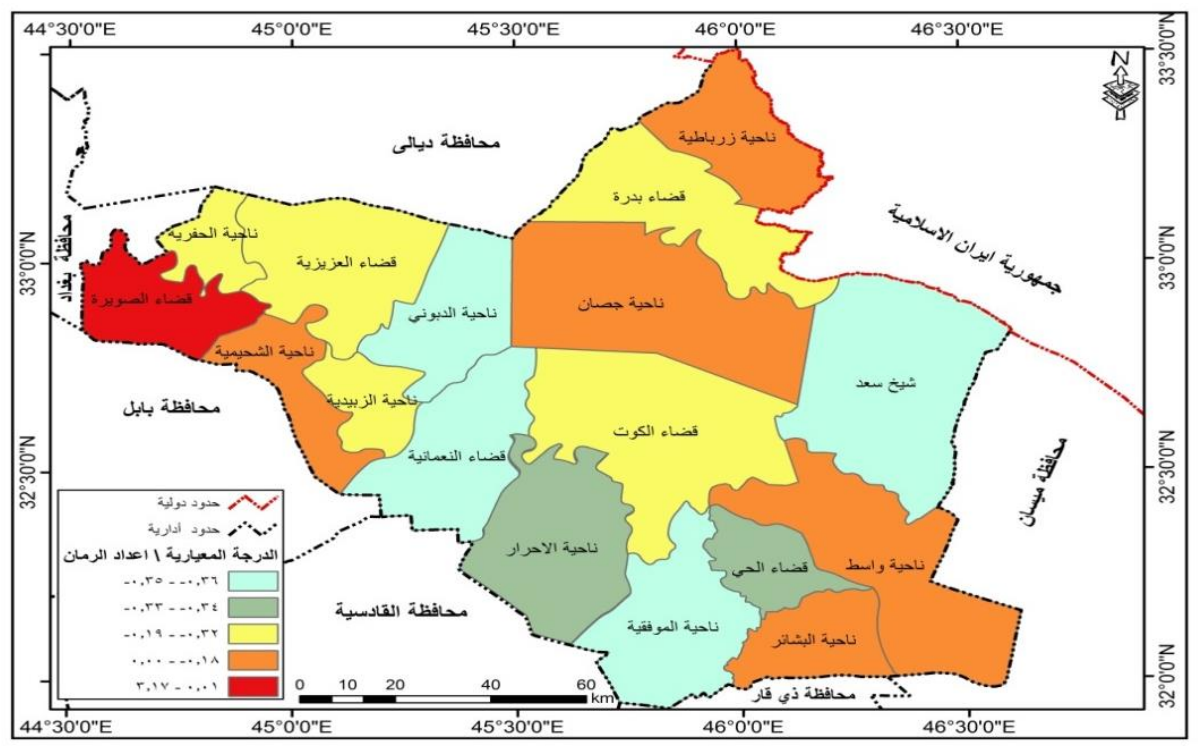

المصدر: من عمل الباحثان بالاعتماد على جدول (؛)

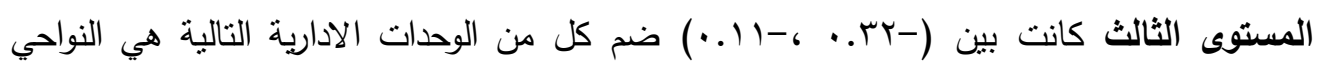

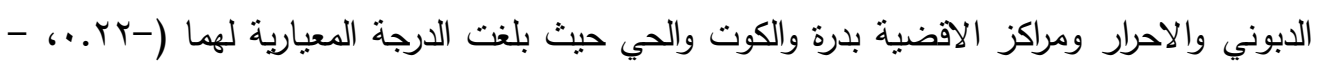

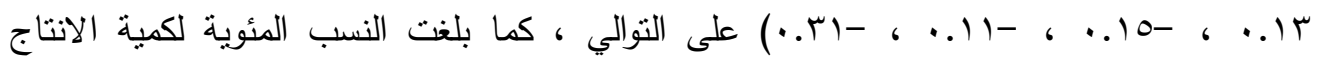

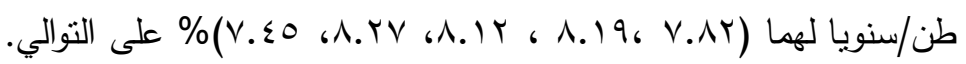

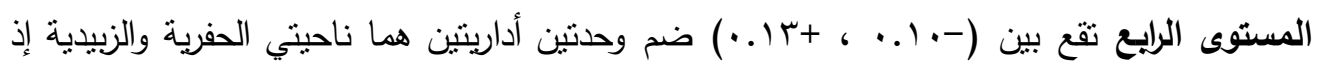

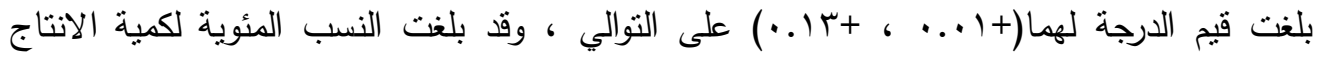

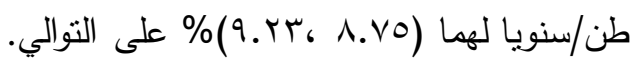

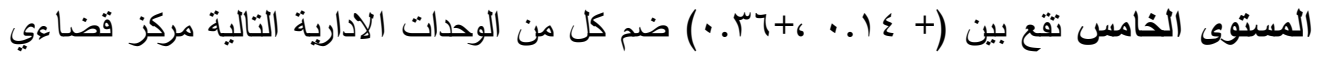

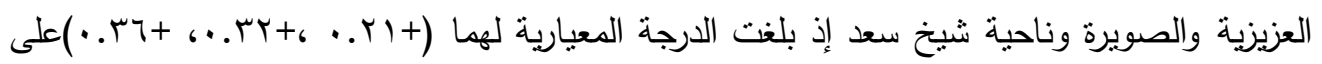

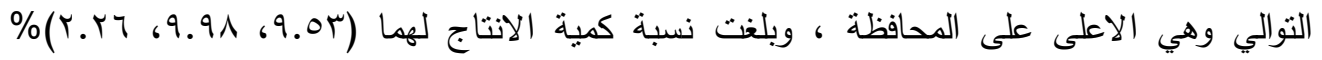
على التوالي. 


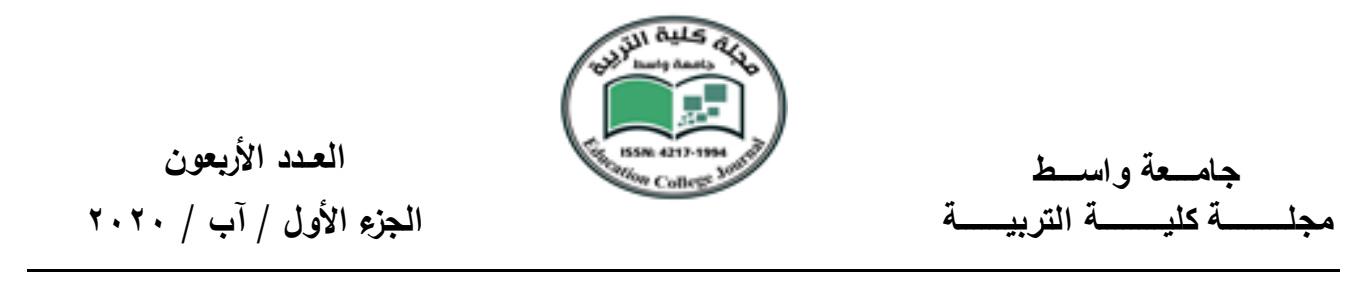

خريطة (0)

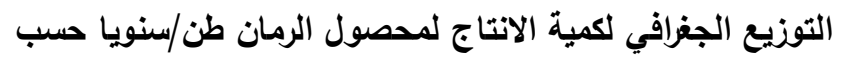

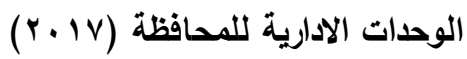

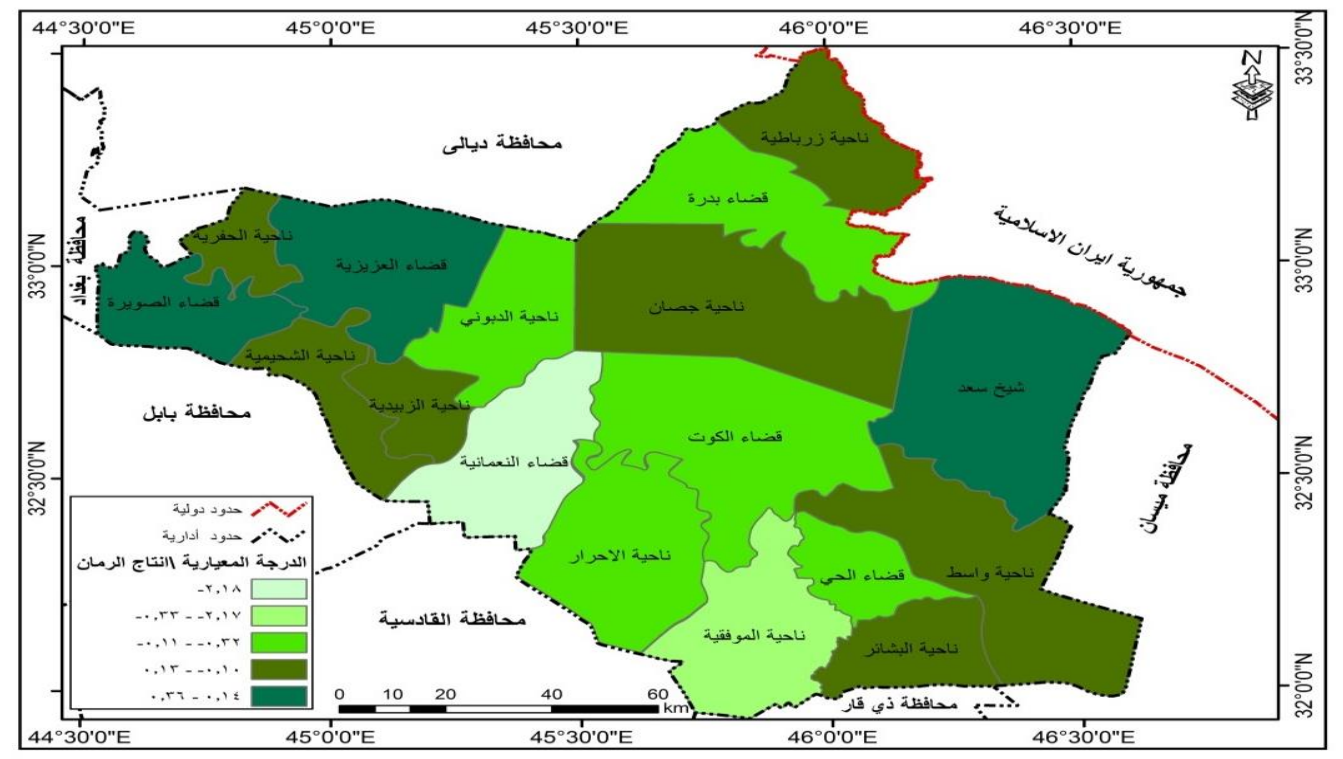

المصدر : من عمل الباحثان بالاعتماد على جدول (؛ ).

Vitaceae العائلة العنية

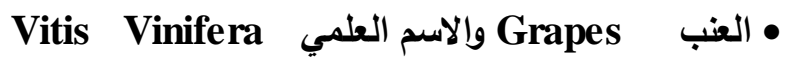

بعد العنب من أثجار المتسلقة و المتساقطة الاوراق وهو نبات صيفي تحتاج فترة نضوجه الى نهار

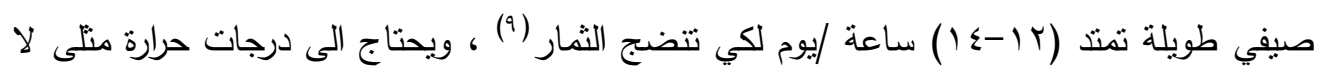

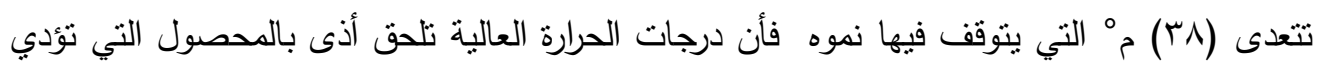

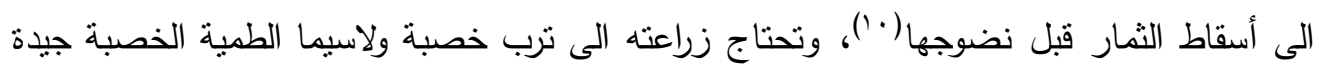

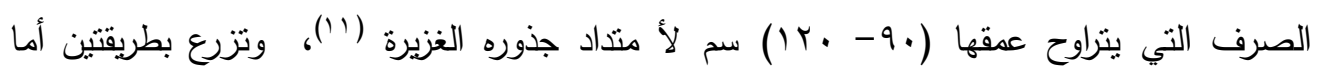

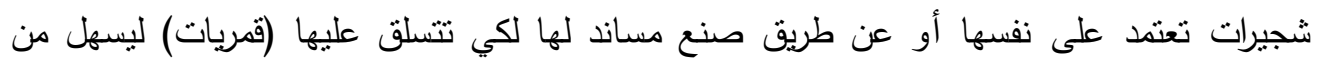

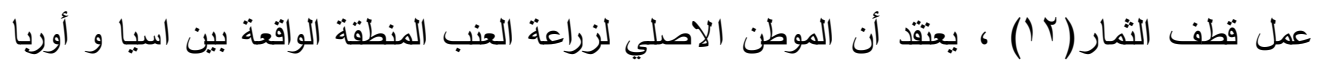

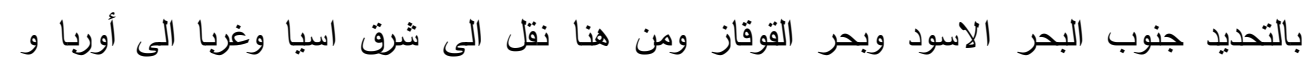
افريقيا(ب (1) ، يعد العنب ذات قيمة غذائية عالية وذلك لأنه يحتوي على كمية كبيرة من السكريات

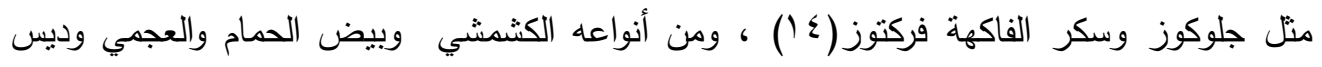


العدد الأربعون

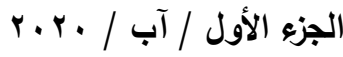

العنز وبلاك همبرك (0) ، تنتشر زراعة العنب في المنطقة الرسوبية من العراق التي تعد محافظة واسط جزء منها إذ تبلغ أعداد الاشجار على مستوى المحافظة (10447) الف شجرة ، إذ تتباين هذه الاعداد مكانيا في منطقة الدراسة الذي أظهرته لنا قيمة الدرجة المعيارية فقد بلغت قيمة الانحراف

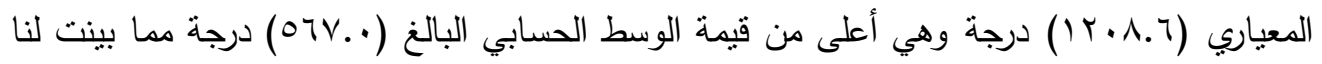
خمس مستويات ، كما مبين من معطيات الجدول (0) والخريطة (†) التي تبين التوزيع الجغرافي

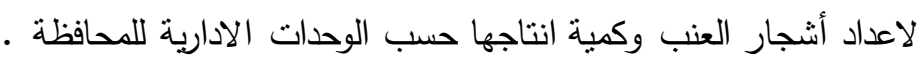

جدول (0)

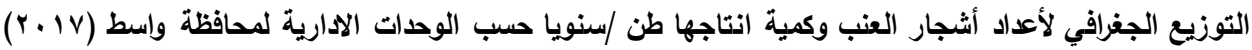

\begin{tabular}{|c|c|c|c|c|c|c|}
\hline$\%$ & الارجة الميارية & كمية الانتاج طن/سنويا & المئوية\% & الدرجة المعيارية & أعداد أثجار & الوحدات الادارية \\
\hline.$\mu^{\prime}$ & $. r v-$ & 9 & T.AV & $. . Y Y-$ & r.. & قضاء الكوت \\
\hline-- & -- & -- & -- & -- & -- & ناحية واسط \\
\hline 0.07 & -0.04 & rvo & 纟.VA & & $0 \ldots$ & ناحية شيخ سعد \\
\hline IV.TI &. r. & $117 \mathrm{~V}$ & 10.51 &..$\leqslant Y-$ & 109. & قضاء النعمانية \\
\hline$\ldots \varepsilon$ &.$\Gamma_{\Lambda \Lambda-}$ & $r$ & 1.rr &. ro- & 159 & ناحية الاحرار \\
\hline$\ldots v$ &. $\mathrm{rAs}^{-}$ & 0 & 1.91 & $. r \cdot-$ & r.. & قضاء الحي \\
\hline r.. \& & $. .10-$ & r.o & 纟.r. & $. .1 \cdot-$ & ¿o. & ناحية الموفقية \\
\hline-- & -- & -- & -- & -- & -- & ناحية البشائر \\
\hline-- & 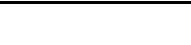 & -- & -- & --- & -- & قضاء بدرة \\
\hline-- & -- & -- & -- & -- & -- & ناحية جصان \\
\hline- & -- & -- & -- & -- & - & ناحية زرياطية \\
\hline or.ry & T.7) & ror. & $\sum \vee . \wedge T$ & T.TV & $0 . .$. & قضاء الصويرة \\
\hline $7 . r V$ & .1 & $\varepsilon r$. & $0 . \leqslant Y$ & $\ldots$ & OTV & ناحية الزبييلية \\
\hline- & -- & $\overline{--}$ & -- & -- & - & ناحية الثحيمية \\
\hline $\mid \leq .71$ &..$V r$ & 910 & $9 . \wedge 7$ & .rर & 1.4 & قضاء العزيزية \\
\hline.$r v$ & . .r4- & ro & $\varepsilon . V A$ & $\ldots .4-$ & $0 .$. & ناحية الحفرية \\
\hline .1 &.$r_{\Lambda-}$ & V & 1.74 & . & iv. & ناحية الابوني \\
\hline $1 \ldots$ & $. r V-$ & $T V \leqslant 1$ & 100 & & $1 \cdot \leq \leqslant V$ & المجموع \\
\hline & 339.0 & & & 567.0 & \multicolumn{2}{|c|}{ الوسط الحسابي } \\
\hline & 883.5 & & & 1208.6 & \multicolumn{2}{|c|}{ الانحراف المعياري } \\
\hline
\end{tabular}

المصلر: من عمل الباحثان بالاعتماد على مديرية زراعة محافظة واسط ، شعبة التخطيط ، بيانات غير 
العدد الأريعون

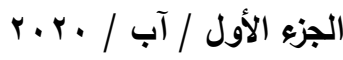

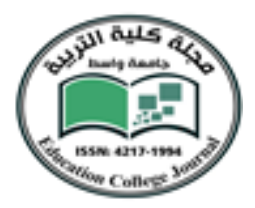

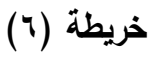

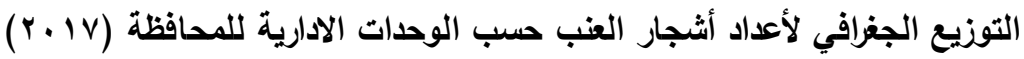

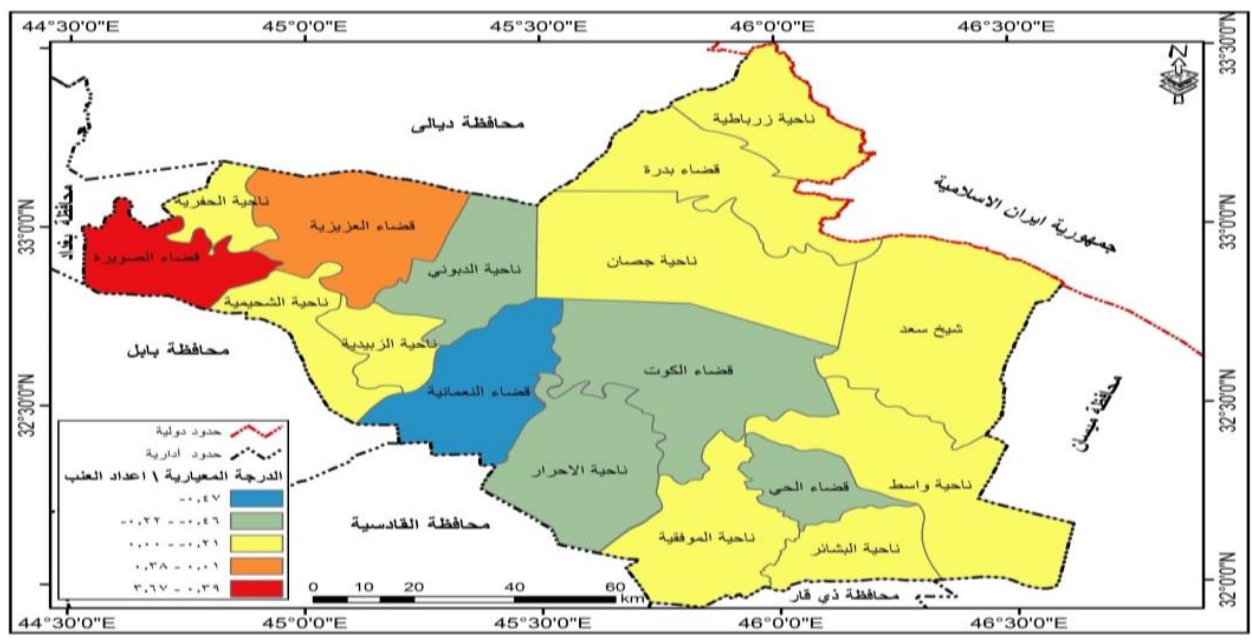

المصلر: من عمل الباحثان بالاعتماد على جدول (ه).

المستوى الاولى تقع ضمن (VV-.. ) ضم وحدة أدارية هي مركز قضاء النعمانية إذ بلغت درجته

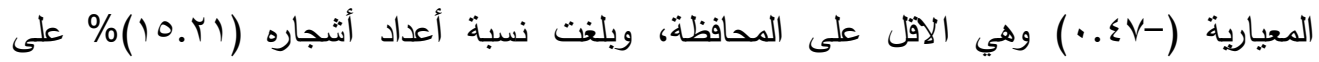

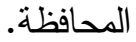

المستوى الثاني كانت بين(-דء.. ، -بr..) ضم كل من الوحدات الادارية التالية ناحيتي الاحرار

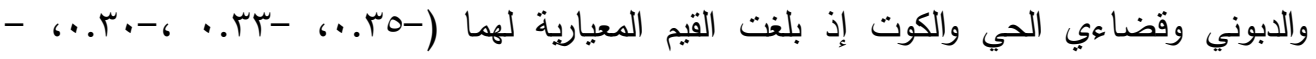
r.r.

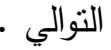

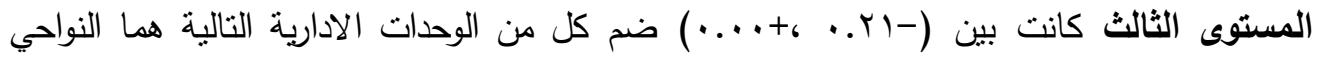
الحفرية والزبيدية والموفقية وشيخ سعد إذ بلغت الدرجة المعيارية لهذه الوحدات (-7 ... ، +......

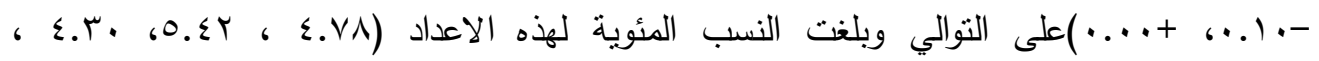

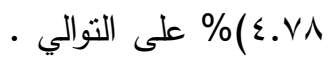

المستوى الرابع تقع بين(+1... ،+^ז..) ضم وحدة ادارية هي مركز قضاء العزيزية إذ بلغت

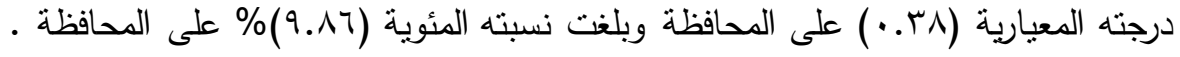


العدد الأربعون

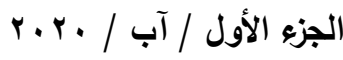

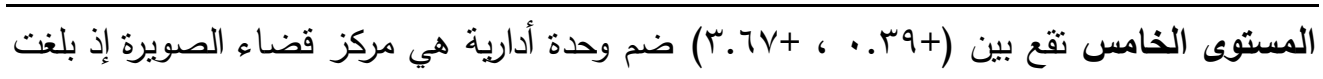
درجته المعيارية (†+T.T) وهو الاعلى على المحافظة ، وبلغت نسبة اعداد الاشجار لهذا القضاء

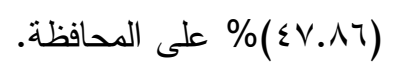

ونجد بأن توزيع أعداد أشجار العنب تتوفر زراعتها في أغلب مناطق الدراسة على الرغم من توفر الظروف البيئية الملائمة لزراعة أشجار العنب في المنطقة الدراسية ويرجح هذا لاسباب نتعلق بقلة الخبرة التي تنطلبها هذه الزراعة فضلا عن نرويج النوع المستورد دون وضع القيود في كمية الاستيراد وزجها في الاسواق المحلية بأسعار تتافسية للمحلي مما تؤدي الى عدم تغطية تكاليف المنتج المحلي لأصحاب البساتين . كما لأعداد أثجار العنب تباينا مكانيا في منطقة الدراسة كان هناك تباينا أيضا في كمية الانتاج لهذا المحصول الذي أظهرته لنا قيمة الدرجة المعيارية نتيجة الفارق بين الانحراف

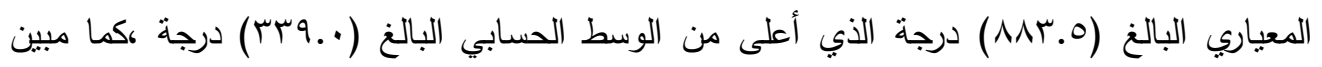

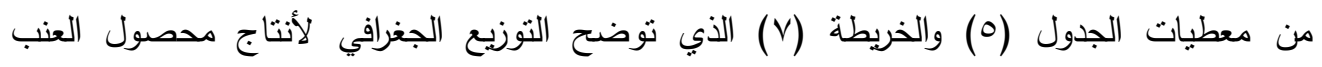
طن/سنويا حسب الوحدات الادارية في واسط الذي بينت لنا خمس مستويات هي المستوى الاولى تقع ضمن (-^ى. • ) ضم كل من الوحدات الادارية التالية ناحيتي الاحرار والدبوني ومركز قضاء النعمانية إذ بلغت الدرجة المعيارية لهما (-یى. ·) على التوالي ، وبلغت نسبة كمية

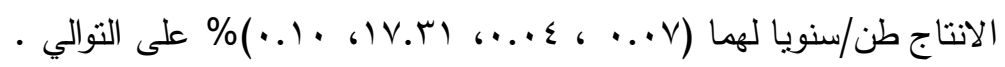

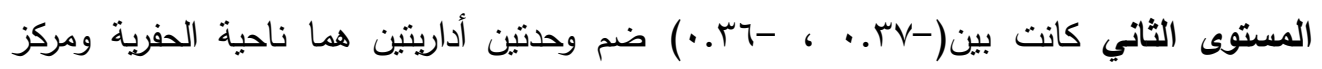

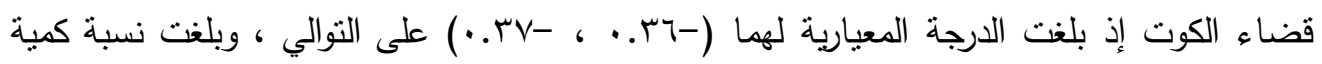

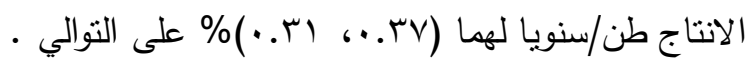
المستوى الثالث كانت بين (-0ب. • ، +. (. •) ضم كل من الوحدات الادارية التالية هما النواحي

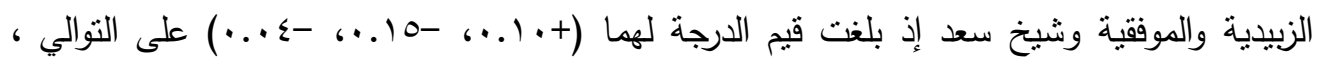

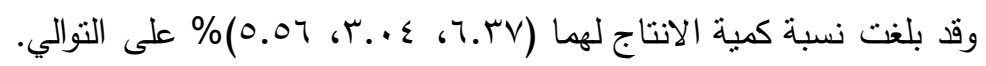

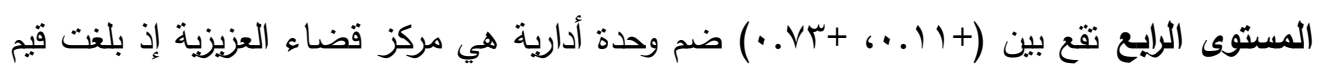

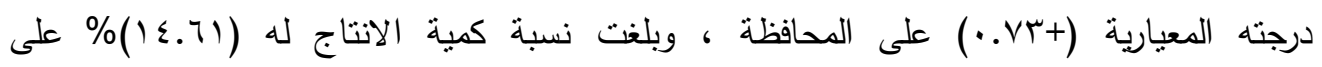
المحافظة .

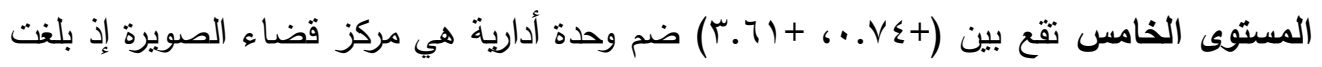
قيم درجته المعيارية (+1.T) وهو الاعلى على المحافظة ، وبلغت نسبة كمية الانتاج لله ( (بr.o)\% على المحافظة .يعد قضاء الصويرة وقضاء العزبزية دن المناطق التي ترتفع بها أعداد 
العدد الأربعون

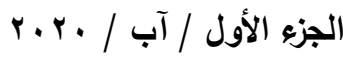

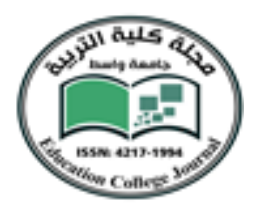

هذه الاشجار دون غيرها من المناطق الاخرى نظرا لما تتوفر ظروف ملائمة لزراعته من مياه

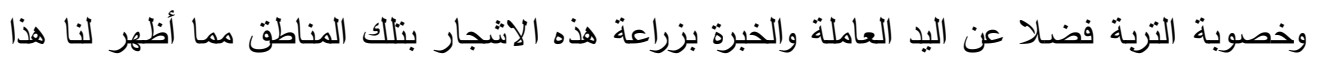

خريطة (v)

التوزيع الجغرافي لكمية محصول العنب انتاج طن /سنويا حسب

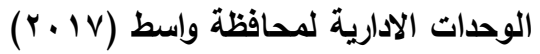

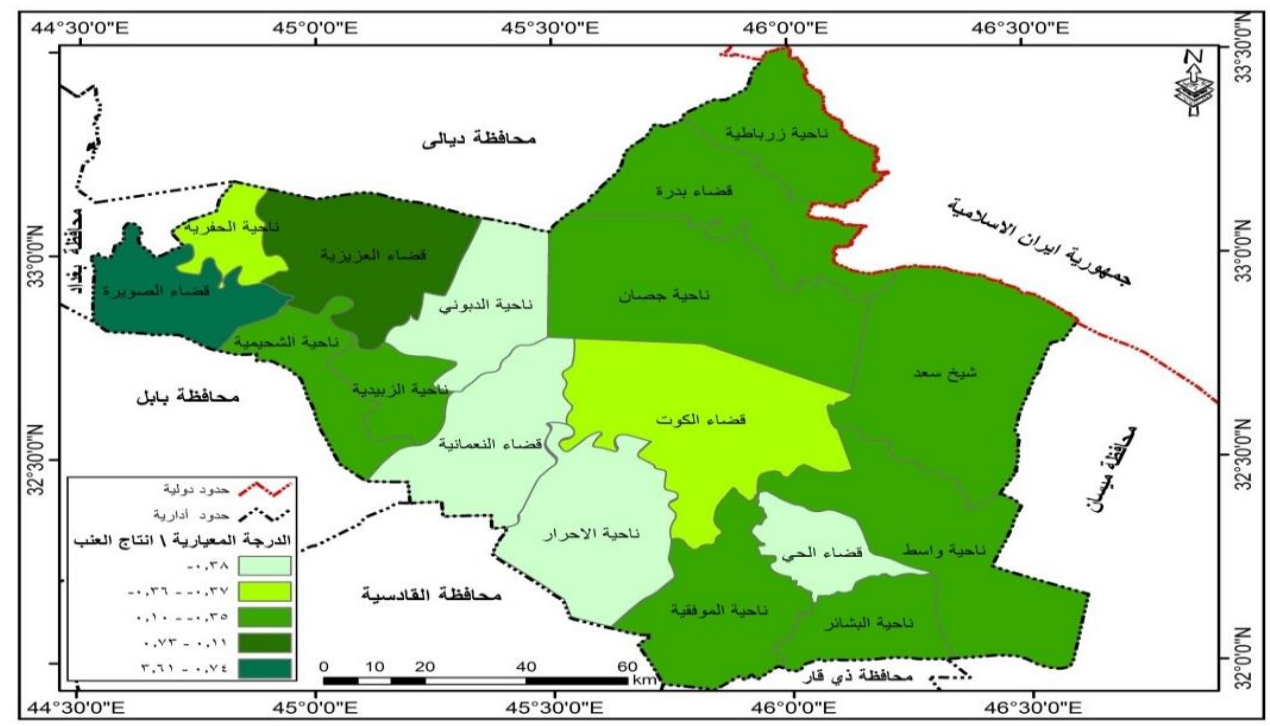

المصدر: من عمل الباحثان بالاعتماد على جدول (0).

الاستتتاجات

ا - أثرت العوامل الطبيعية في توزيع أشجار الرمانيات والعنب في منطقة الدراسة من نوعية السطح وعناصر مناخية ونوعية الترب التي تحتاجها هذه الزراعة فضلا عن توفر المياه الدائمة مع تقليل أثنار النبات الطبيعي عن طريق تتظيف البساتين والعناية بها ـ التهاته r - كما تتأثز هذه الزراعة بالعوامل البشرية ولاسيما اليد العاملة والخبرة وتوفير طرق النقل وتسويق ثمار الرمانيات والعنب وتوفير الاسمدة التي تتطلبها هذه الاشجار في مراحل نموها حتى نضجها. r - اما العوامل الحياتية فهي لاتقل أثرا عن بقي العوامل الاخرى اذ تعد الآفات والامراض والحشرات التي تتعرض لها هذه الاشجار من أسوء العوامل إذ تقضي على الاشجار وثمارها في مدة قصيرة مما تسبب اضرار اقتصادية فضلا عن موت الكثير من الاثجار • 
العدد الأربعون

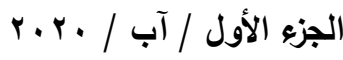

ع - تعد أشجار الرمانيات والعنب من الاشجار التي توفر الغذاء الاساسي للسكان فضلا عن أهميتها الاقتصادية للمزارعين فهي ذات قيمة غذائية جيدة لأحتوائها عناصر غذائية من فيتامينات • ومعادن وماء وسكر

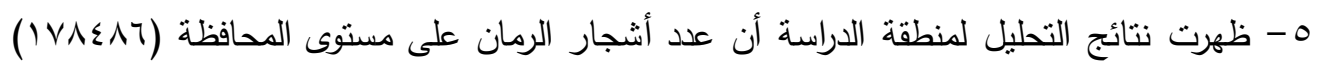
الف شجرة ، وهي تتباين هذه الاعداد من منطقة الى أخرى ، وجاء مركز قضاء الصويرة أذ بلغت درجته المعيارية (V+ (Y+) وهو الاعلى على المحافظة نتيجة توفر الظروف الملائمة

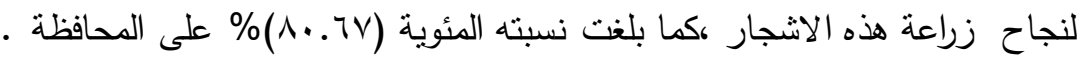
7 - كما أظهرت نتائج التحليل لمنطقة الدراسة أن أعلى كمية أنتاج طن /سنويا لهذه لأشجار الرمان لأنهان على مستوى المحافظة الوحدات الادارية التالية مركز قضاءي العزيزية والصويرة وناحية شيخ

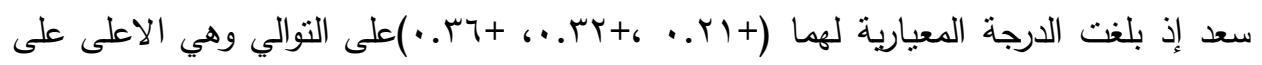

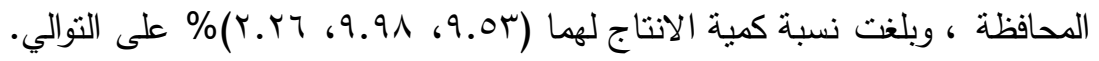
V- ظهرت نتائج التحليل لمنطقة الدراسة أن عدد أشجار العنب (10447) الف شجرة وهذه الأعداد جاءت منباينة مكانيا من منطقة الى أخرى ، وجاءت الوحدة الأدارية مركز قضاء الصويرة إذ بلغت درجته المعيارية (T+.T+) وهو الاعلى على المحافظة ، وبلغت نسبة اعداد الاشجار لهذا

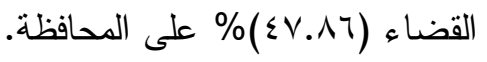
^- اما كمية الانتاج طن / سنويا لأشجار العنب فقد كانت أعلى في الوحدة الأدارية مركز قضاء الصويرة إذ بلغت قيم درجته المعيارية (+(1.ب) وهو الاعلى على المحافظة ، وبلغت نسبة كمية الانتاج له (بr.or)\% على المحافظة . الحلول والمعالجات

1 - أختيار أصناف من أشجار الرمانيات والعنب ممن تتحمل الظروف المناخية بمنطقة الدراسة بأستخدام التهجين وأجراء البحوث والدراسات المختبرية . r- حماية المنتج المحلي من خلال نوفير الاسواق وتزويجه والحد من أسنيراد المنتج وفرض الضرائب عليها r- حماية أثجار البساتين ولاسيما اشجار الرمانيات والعنب من خلال ش ش المبيدات والقضاء على

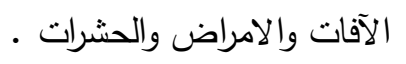

ع - أهتمام سياسية الدولة للبساتين والمزارعين وتنهيل لهم القروض وتوفير الاسمدة والمبيدات والآلآت بأسعار رمزية . 
العدد الأربعون

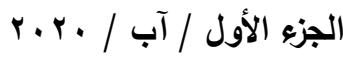

ه- أجراء الندوات بين الحين والاخر بين المزارعين من قبل الجمعيات الفلاحية لتوضح لهم السبل الحديثة والخبرة في زراعة هذه الاشجار ل الشاء

المصادر

(') حسين حميد كريم ، النأريخ الجيولوجي الحديث لسهل وادي الرافدين الجنوبي ، مجلة الخليج العربي، مركز دراسات

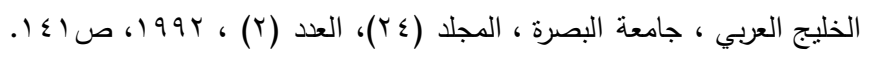

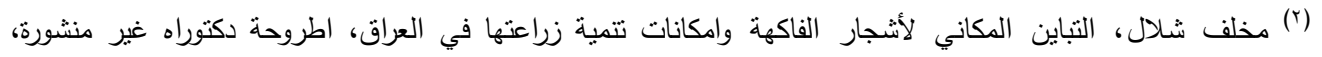

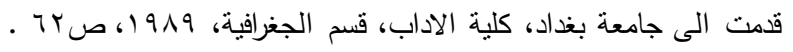

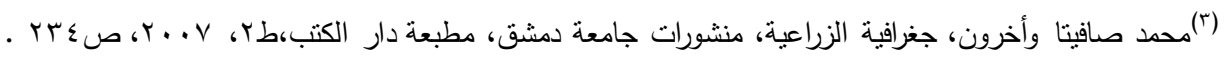

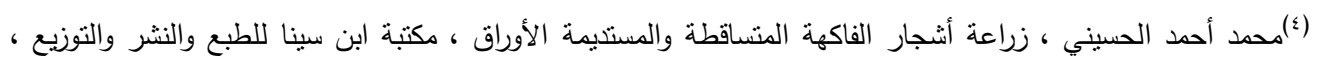

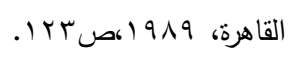

(0)قحطان حسين الجوذري ، أثز المناخ في زراعة أثجار الفاكهة في قضاء القاسم، رسالة ماجستير(غير منشورة)كلية

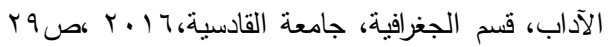

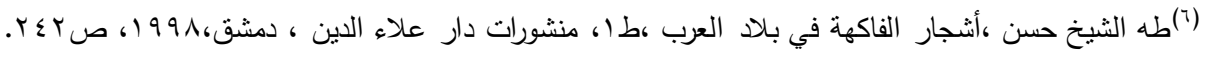

(V)

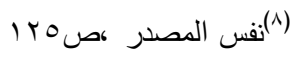

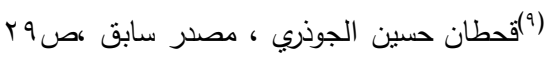

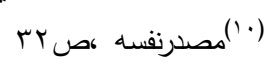

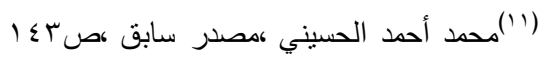

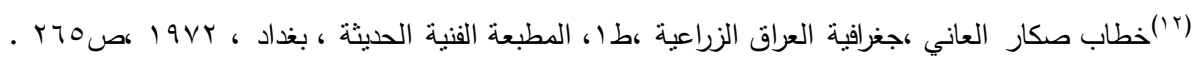

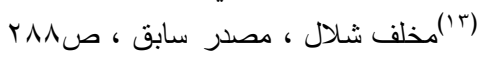

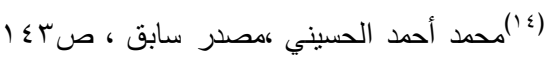

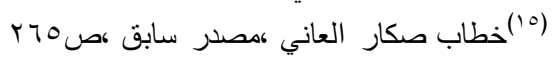

